\title{
SISTEM INFORMASI SURAT PENGANTAR BERBASIS WEB (Studi Kasus: KELURAHAN SUKASARI TANGERANG)
}

\author{
Janu Ilham Saputro *1, Putri Ika Wati ${ }^{2}$, Rulita Octipany ${ }^{3}$ \\ 1,2,3 Program Studi Sistem Informasi Universitas Raharja \\ e-mail: *1 janu@raharja.info, ${ }^{2}$ putri.ika@raharja.info, ${ }_{2}^{3}$ rulita.octipany@raharja.info
}

\begin{abstract}
Abstrak
Pada kelurahan Sukasari Kota Tangerang selama ini mempunyai sistem informasi yang masih sederhana dan kurang efektif yaitu masih menggunakan Ms.Word/Ms.Excel. Sistem tersebut tentu saja tidak efektif karena mempunyai banyak kelemahan salah satunya yaitu harus mencari file surat dalam beberapa folder tertentu, dan juga sering terjadi kehilangan file/folder surat serta penumpukan berkas-berkas, dan mengakibatkan lamanya proses dalam pencarian maupun pembuatan surat pengantar serta laporan yang dibutuhkan. Sehingga dibutuhkan sistem yang dapat mengurangi kelemahan tersebut. Metode analisa yang digunakan oleh penulis disini yaitu menggunakan analisa SDLC (System Development Life Cycle), untuk metode perancangan modelnya menggunakan UML (Unified Modeling Language).. Dengan demikian akan menghasilkan sistem informasi surat yang dapat bermanfaat bagi Kelurahan Sukasari baik sebagai pengetahuan maupun sebagai dasar untuk mengambil suatu langkah kebijaksanaan. Sehingga dapat meningkatkan pelayanan kepada masyarakat.
\end{abstract}

Kata Kunci: Surat Pengantar, Ms.Excel, Laporan, SDLC, HTML

\begin{abstract}
In Sukasari, Tangerang City, all this time has a simple and ineffective information system that is still using Ms. Word / Ms. Excel. The system is of course ineffective because it has many weaknesses, one of which is having to search for mail files in a number of specific folders, and also often loses file / letter folders and buildup of files, and results in a long process of searching and creating a cover letter and report that needed. So we need a system that can reduce these weaknesses. The analysis method used by the author here is using SDLC (System Development Life Cycle) analysis, for the method of designing the model using UML (Unified Modeling Language). to take a step of wisdom. So that it can improve services to the community.
\end{abstract}

Keywords: Cover Letter, Ms. Excel, Report, SDLC, HTML

\section{PENDAHULUAN}

Perkembangan dunia teknologi sekarang ini baik di instansi pemerintahan maupun swasta dituntut untuk dapat mengikuti serta mengetahui derasnya arus informasi dalam segala bidang khususnya bidang computer demi mempermudah pekerjaan karyawan dan meningkatkan kepuasan pelanggan. 
Pada saat ini, masih terdapat beberapa instansi pemerintah yang masih menggunakan sistem manual dalam menyelesaikan pekerjaan. Salah satunya yaitu pada Kelurahan Sukasari yang hingga saat ini masih menggunakan sistem manual atau pengolahan data menggunakan Ms.Word \& Ms. Excel dalam pembuatan surat pengantar yang dibutuhkan masyarakat sehingga mengakibatkan lamanya proses pembuatan surat pengantar, maupun pencarian surat pengantar yang dibutuhkan oleh masyarakat.

PERMASALAHAN

Permasalahan yang dihadapi pada sistem yang berjalan saat ini yaitu :

a) Pengolahan data belum terintegrasi

Sistem informasi surat pengantar yang sedang berjalan saat ini dalam proses pengolahan datanya masih belum optimal, sehingga pengolahan data belum diperoleh secara cepat, tepat dan akurat serta belum berjalan secara efektif dan efisien.

b) Pembuatan surat belum menggunakan database.

Proses pembuatan surat pengantar yang dibutuhkan masih menggunakan sistem komputer yang sederhana yaitu Ms.Excel/Ms.Word. Sehingga pada proses pembuatan surat sering terjadi kesalahan input atau yang lebih sering disebabkan karena human error.

c) Pembuatan surat pengantar tidak tertata

Dalam proses pembuatan surat pengantar, Kelurahan hanya membuat dan mencetak tanpa adanya laporan akhir dalam bentuk data sehingga menyebabkan terjadinya beberapa kesalahan seperti surat hilang dan double surat.

Dari permasalahan tersebut dengan adanya sistem informasi surat pengantar berbasis web diharapkan dapat membantu masyarakat dan mempermudah staff dalam proses pembuatan surat pengantar. Dan dengan sistem ini, diharapkan instansi tersebut dapat meningkatkan kualitas pelayanan publik menjadi lebih baik.

\section{METODE PENELITIAN}

Metode penelitian yang digunakan adalah :

\section{Observasi}

Melakukan pengumpulan data dengan pengamatan langsung ke Kelurahan Sukasarari untuk mendapatkan data yang di teliti dan untuk mengetahui sistem yang sudah berjalan dan menganalisis secara sistematis terhadap unsur-unsur yang diteliti.

\section{Wawancara}

Metode ini dilakukan oleh peneliti dengan proses mewawancarai bagian Seksi Tata Pemerintahan, Sekretariat, dan Lurah secara langsung kepada pihak Kelurahan Sukasari yang bersangkutan dalam proses pelayanan sistem surat pengantar yang sedang berjalan saat ini untuk mendapatkan informasi yang akurat dan untuk menyelesaikan penelitian ini.

\section{Studi Pustaka}

Peneliti melakukanan observasi dan wawancara dilakukan juga dengan mencari dan membaca beberapa referensi dari perpustakaan dan internet untuk mendapatkan informasi atau sumber-sumber kajian yang terkait dengan permasalahan yang sedang dibahas.

\section{Metode Analisis}

Pada metode analisa sistem ini, peneliti menggunakan metode analisa SWOT untuk mengetahui permasalahan ataupun suatu topik dari 4 sisi yang berbeda diantaranya, Strenght (S) atau disebut sebagai analisis kekuatan, Weaknesses (W) atau disebut sebagai kelemahan, Opportunity (O) atau disebut sebagai analisis peluang, Threats (T) atau disebut sebagai analisis ancaman. Dengan menggunakan metode analisa ini maka penelitian dapat dianalisis dengan teknik-teknik yang tepat dalam hal ini sistem informasi surat pengantar. 


\section{Metode Perancangan}

Metode perancangan yang dilakukan oleh penulis yaitu menggunakan metode permodelan secara visual untuk sarana perancangan sistem yang berorientasi objek dengan UML (Unified Modeling Language) untuk sistem yang akan dibuat dalam hal ini sistem informasi surat pengantar.

\section{LANDASAN TEORI}

\section{Sistem}

Menurut Hengki Tamando Sitohang dalam jurnal Informatik Pelita Nusantara (2018:7), "Sistem adalah suatu jaringan kerja dari prosedur-prosedurnya yang saling berhubungan, berukmpul bersama-sama untuk melakukan suatu kegiatan atau untuk menyelesaikan suatu sasaran tertentu."

\section{Data}

Menurut Martono dkk dalam jurnal CCIT (2017:231), "Data adalah deskripsi tentang benda, kejadian, aktifitas, dan transaksi, yang tidak mempunyai makna atau tidak berpengaruh secara langsung kepada pemakai".

\section{Informasi}

Menurut Abidin yang dikutip oleh Priyo Sutopo, Dedi Cahyadi, dan Zainal Arifin dalam Jurnal Informatika Mulawarman (2016:24), [4] "Informasi adalah data yang diolah menjadi bentuk yang berguna dan menjadi berarti bagi penerimanya".

\section{Sistem Informasi}

Menurut Rosmalia dkk dalam jurnal SemanTIK (2016:228), "Sistem informasi adalah suatu sistem didalam suatu organisasi yang merupakan kombinasi dari orang-orang, fasilitas, teknologi,media prosedur-prosedur dan pengendalian yang ditujukan untuk mendapatkan jalur komunikasi penting, memproses tipe transaksi rute tertentu, memberi sinyal kepada manajemen dan yang lainnya terhadap kejadian-kejadian internal dan eksternal yang penting dan menyediakan suatu dasar informasi untuk pengambilan keputusan yang cerdik".

\section{Surat}

Menurut Meliana yang dikutip oleh Joko Agus Prawono dan Anton Respati Pamungkas dalam Jurnal INFORMATIKA (2015:27) , surat adalah informasi tertulus yang dapat diperguanakan sebagai alat komunikasi tulisan yang dibuat dengan persyaratan tertentu yang khusus yang berlaku untuk surat menyurat.

\section{Fungsi surat}

Fungsi surat menurut Hengki Tamando Sitohang dalam jurnal Informatik Pelita Nusantara (2018:7), "Adalah sebagai sarana dalam penyampaian pesan secara tertulis, surat berperan dalam mencapai tujuan suatu instansi atau organisasi dalam menjalin kerjasama antar organisasi/instansi. Sebagai pemberitahuan, sebagai surat perintah, sebagai surat peringatan, Sebagai surat permohonan atau permintaan, sebagai surat pengantar, sebagai surat perjanjian, Sebagai surat laporan, Sebagai surat keputusan, sebagai surat panggilan, sebagai surat susulan". 


\section{Unified Modeling Language (UML)}

Menurut Ahmad Wahyudin yang dikutip oleh Dewi Kusumawati dan Dwi Setiyani dalam jurnal JESIK, (2017:23) "UML (Unified Modeling Language) adalah suatu bahasa standar untuk menjelaskan dan memvisualisaikan artifak dari proses analisis dan desain yang berorientasi objek. UML menyediakan standar dalam bentuk notasi dan diagram untuk memodelkan suatu sistem".

\subsubsection{Pengacuan Pustaka}

Berikut penelitian yang telah dilakukan dan memiliki keterkaitan dengan penelitian yang akan dibahas:

1. Penelitian yang dilakukan oleh Defi Anggraeni dan Siska Iriani [2016]. Penelitian yang dilakukan oleh Defi Anggraeni dan Siska Iriani dalam jurnal Bianglala InformatikaVol.4 No.2 (2016), yang berjudul "Sistem Informasi Pengarsipan Surat Masuk dan Surat Keluar Pada Kantor Kecamatan Pringkulu" . Peneliti menjelaskan bahwa metode penelitian yang digunakan yaitu : pengumpulan data, analisis sistem, perancangan sistem dan implementasi sistem yang digambarkan dalam perancangan DFD (Data Flow Diagram) dan bertujuan untuk menghasilkan sistem informasi pengarsipan surat masuk dan surat keluar pada kantor Kecamatan Pringkulu sehingga diharapkan dapat mempermudah sistem kearsipan dan meminimalisasi kesulitan pencarian berkas.

2. Penelitian yang dilakukan oleh Yudie Irawan [2015]. Peneltian yang dilakukan oleh Yudie Irawan dalam jurnal SIMETRIS Vol.6 No.1 (2015), yang berjudul "Analisa Dan Perancangan Otomatisasi Surat Pengantar RT Berbasis Sms Gateway Sebagai Penerapan Konsep Paperless Office". Perancangan pada penelitian ini dibuat teknologi aplikasi SMS gateway untuk menggantikan surat pengantar RT untuk memudahkan proses permohonan. Metode penelitian pada pengembangan sistem ini berdasarkan metode pengembangan sistem Waterfall model, sedangkan dalam level desain menggunakan metode perancangan sistem Unified Modelling Language. Hasil penelitian berupa pemodelan sistem yang disajikan dalam Business Use Case Diagram, Use Case Diagram dan Class Diagram, sedangkan perancangan basisdata ditampilkan dalam ER diagram.

3. Penelitian yang dilakukan oleh Khozin Yuliana dkk [2016]. Peneltian yang dilakukan oleh Khozin Yuliana dkk dalam jurnal SENSI 005 ISSN Vol.2 No.2 [2016], yang berjudul "Rancang Bangun Aplikasi Sistem Informasi Inventarisasi Surat Masuk dan Surat Keluar Berbasis Web". Penelitian ini dilakukan untuk mengetahui sistem inventarisasi surat masuk dan surat keluar agar dapat membantu proses manajemen sistem surat masuk dan keluar yang lebih baik. Maka penelitian ini melakukan analisis yang hasilnya digambarkan dalam Unified Modeling Language (UML) dengan menggunakan software Visual Paradigm 6.4, proses pembuatan sistem menggunakan software PHP dan database MySQL sehingga dapat dengan mudah mengolah data (menginput, mengubah, dan menghapus data) tanpa harus memakan waktu yang sangat lama, sampai menyajikannya menjadi informasi yang dibutuhkan user dengan akurat, efektif, dan efisien.

\section{HASIL DAN PEMBAHASAN}

Dalam penelitian ini, akan dijelaskan mengenai rancangan sistem pengolahan pembuatan surat pengantar pada kelurahan Sukasari Tangerang. Dalam penelitian ini, penulis merancang sistem usulan yang dapat membantu kegiatan operasional dalam pelayanan pembuatan surat pengantar sampai dengan prosedur pencetakan serta laporan surat pengantar oleh masyarakat. Proses pembuatan surat pengantar sampai dengan prosedur pencetakan serta laporan surat pengantar yang dibutuhkan akan lebih mudah. Serta laporan yang dihasilkan akan lebih efektif. Dalam rancangan ini, proses peng-input-an data dilakukan dengan seksi Tata 
Pemerintahan melakukan penginputan data pada form buat surat sesuai dengan kebutuhan surat yang diinginkan Setelah proses penginputan data selesai dan disimpan, maka Seksi Tata Pemerintahan dapat melakukan pencetakan surat tersebut. Setelah itu akan dilanjutkan dengan prosedur data laporan, yaitu bagian Seksi Tata Pemerintahan, Sekretariat, dan Lurah dapat melihat dan mencetak laporan jika diperlukan. Pada penulisan jurnal ilmiah ini, ruang lingkup penelitian diantaranya yaitu:

1. Rancangan sistem informasi surat pengantar berbasis web pada kelurahan Sukasari Kecamatan Tangerang dalam membantu kegiatan operasional pelayanan arsip.

2. Proses pembuatan surat pengantar yang menjadi lebih mudah untuk diakses dimana saja, kapan saja, dan oleh siapa saja.

3. Proses penyimpanan laporan yang menjadi lebih rapi.

Dalam rancangan sistem yang diusulkan yang dapat dijelaskan pada use case diagram, activity diagram, sequence diagram dan class diagram dengan menggunakan Visual Paradigm for UML 6.4 Enterprise Edition.

Analisis SWOT

Dalam penelitian ini, peneliti menggunakan metode analisis SWOT dimana analisis ini mengidentifikasi kekuatan (strenght) dan kelemahan (weakness) yang merupakan faktor lingkungan internal serta faktor lingkungan eksternal yaitu kesempatan (opportunities) dan ancaman (threat). Berikut hasil analisa SWOT sistem yang berjalan:

Tabel 1. Analisis SWOT

\begin{tabular}{|c|l|}
\hline \multicolumn{1}{|c|}{ Strenght } & \multicolumn{1}{|c|}{ Weaknesses } \\
$\begin{array}{l}\text { 1.Dapat dilakukan semua } \\
\text { pegawai. } \\
\begin{array}{l}\text { 2.Semua komputer di kelurahan } \\
\text { sudah terhubung internet }\end{array}\end{array}$ & $\begin{array}{l}\text { 1.Membutuhkan waktu yang lama } \\
\text { dalam proses pencarian surat } \\
\text { pengantar. } \\
\text { 2.Sistem pembuatan surat masih } \\
\text { dilakukan dengan Ms.Word/Ms.Excel. }\end{array}$ \\
\hline \multicolumn{1}{|c|}{ Opportunities } & \multicolumn{1}{|c|}{ Threats } \\
$\begin{array}{l}\text { 1.Adanya sistem pembuatan } \\
\text { surat berbasis web }\end{array}$ & $\begin{array}{l}\text { 1.Hilangnya file surat pengantar. } \\
\text { 2.Jika server rusak maka pembuatan } \\
\text { surat pengantar tidak dapat dilakukan. }\end{array}$ \\
& \\
\hline
\end{tabular}

\section{Use Case Diagram Sistem Informasi pembutan surat pengantar}

Gambar 1 dibawah ini adalah Use Case Diagram untuk menggambarkan secara umum Sistem pembuatan surat pengantar saat ini yang menggambarkan alur sistem dengan use case dan aktoraktor (user) yang terlibat. Yang berdasarkan diagram tersebut, terdapat 4 yang dapat melakukan kegiatan didalam sistem, diantaranya yaitu Warga, Staff Pendaftaran, Seksi Tata Pemerintahan, dan Lurah. Dan juga terdapat 6 (enam) Use Case yang dapat dilakukan oleh Actor tersebut, diantaranya Membawa Formulir, Memeriksa Kelengkapan Form, Membuat Surat yang dibutuhkan, Cetak Surat, Meminta Legalisir dan TTD Surat, Surat Pengantar Selesai. 


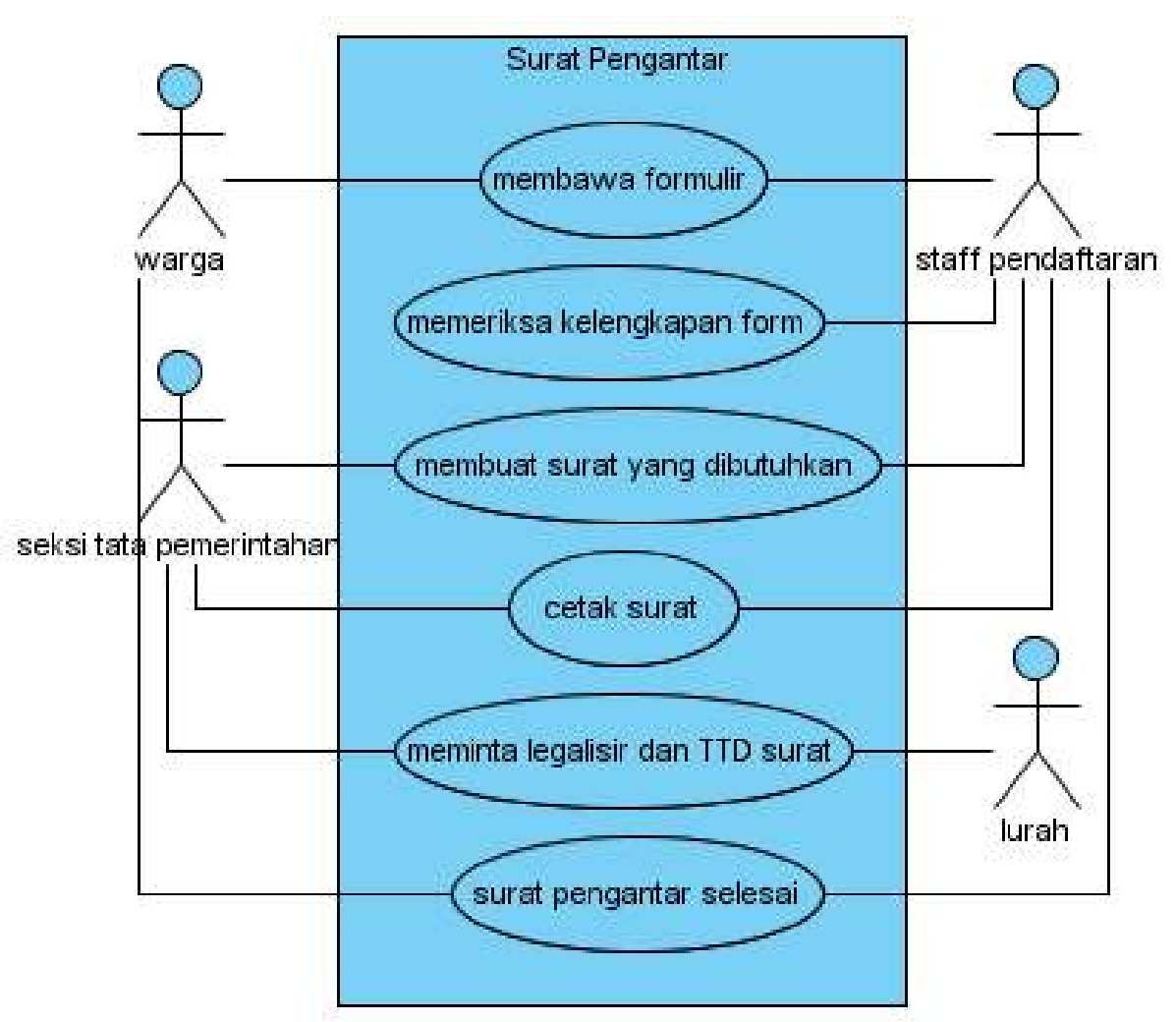

Gambar 1. Use Case Sistem Informasi pelayanan Arsip

\section{RANCANGAN SISTEM}

Untuk mengatasi masalah yang ada saat ini, dibutuhkan rancangan Sistem Informasi untuk surat pengantar berbasis web sehingga, pemohon yang ingin membuat surat pengantar dapat melakukannya di mana saja dan kapan saja. Data-data keperluan pemohon dapat langsung diinput pada sistem serta surat dapat langsung di cetak pada sistem sehingga lebih efektif dan efisien. Serta surat yang dibutuhkan pemohon dapat langsung di proses melalui sistem. Dengan cara ini pemohon dapat lebih cepat menyelesaikan keperluan nya. Pada sistem ini pula, admin dapat dengan mudah mengelola data pemohon. Register pemohon dapat langsung dilakukan pada sistem sehingga tidak ada penumpukan berkas. Sistem ini tentunya terintegrasi pada Data yang terintegrasi dapat menghasilkan laporan surat pengantar yang cepat, dan akurat.

\section{Use Case Diagram}

Di bawah ini adalah Use Case Diagram Rancangan Sistem Informasi Surat Pengantar Berbasis Web yang menggambarkan alur sistem dengan use case dan aktor-aktor yang terlibat : 


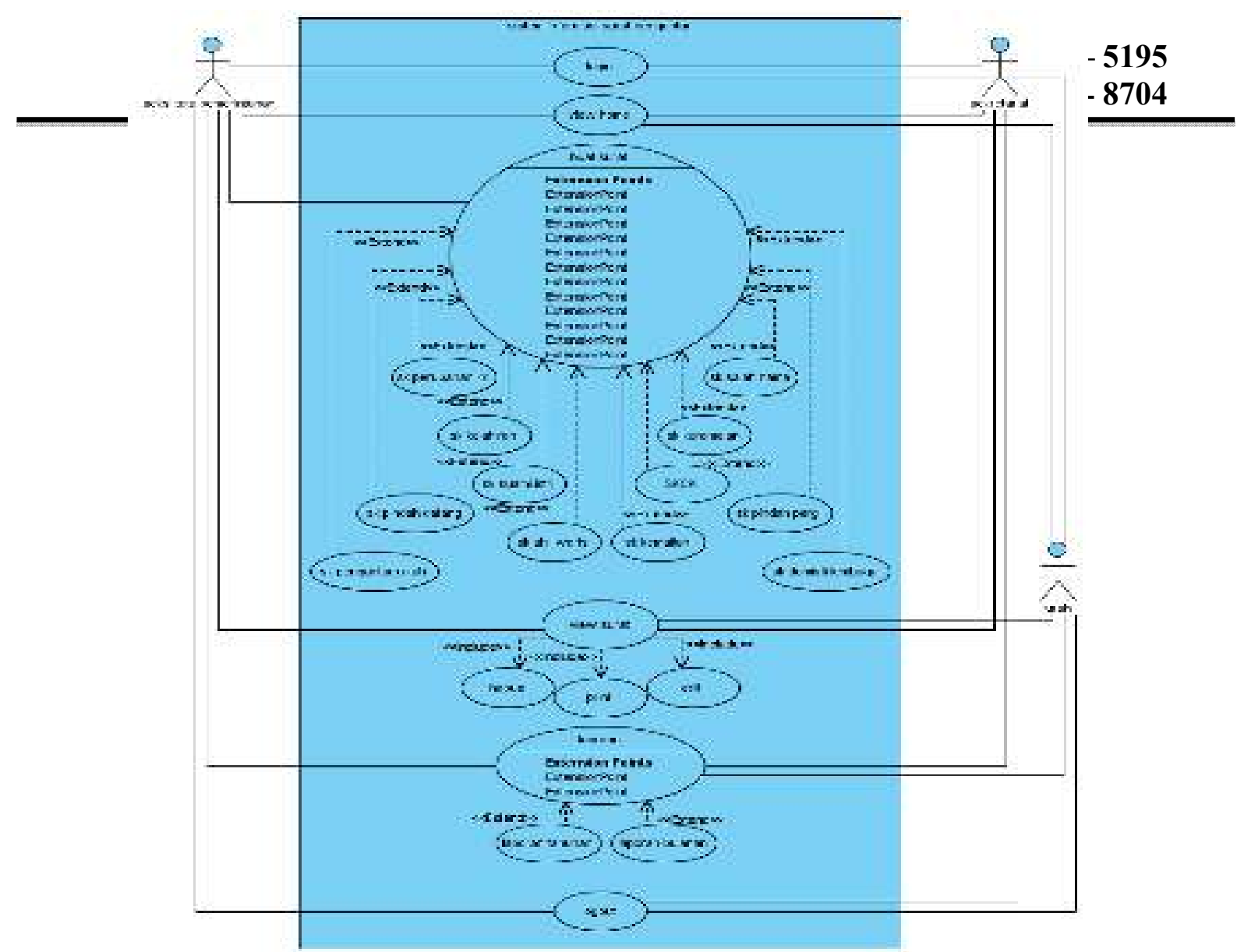

Gambar 2. Use Case rancangan Sistem Informasi Surat Pengantar

Dari diagram di atas, terdapat 1(satu) sistem yang mencakup seluruh kegiatan dalam proses penginputan, 3 (tiga) actor yang melakukan kegiatan yaitu bagian Seksi Tata Pemerintahan, Sekretariat, dan Lurah, dan 6 usecase yang akan dilakukan oleh aktor tersebut, seperti login, View Home, Buat Surat, View Surat, Laporan, Logout.

\section{Class Diagram}

Diagram Kelas (class diagram) sangat membantu dalam visualisasi kelas dari suatu sistem. Hal ini di sebabkan karena class adalah deskripsi kelompok objek-objek dengan atribut (property) dan relasi yang sama. Disamping itu class diagram bisa memberikan pandangan global atas sebuah system. Berikut class diagram Sistem Informasi Surat Pengantar berbasis web: 

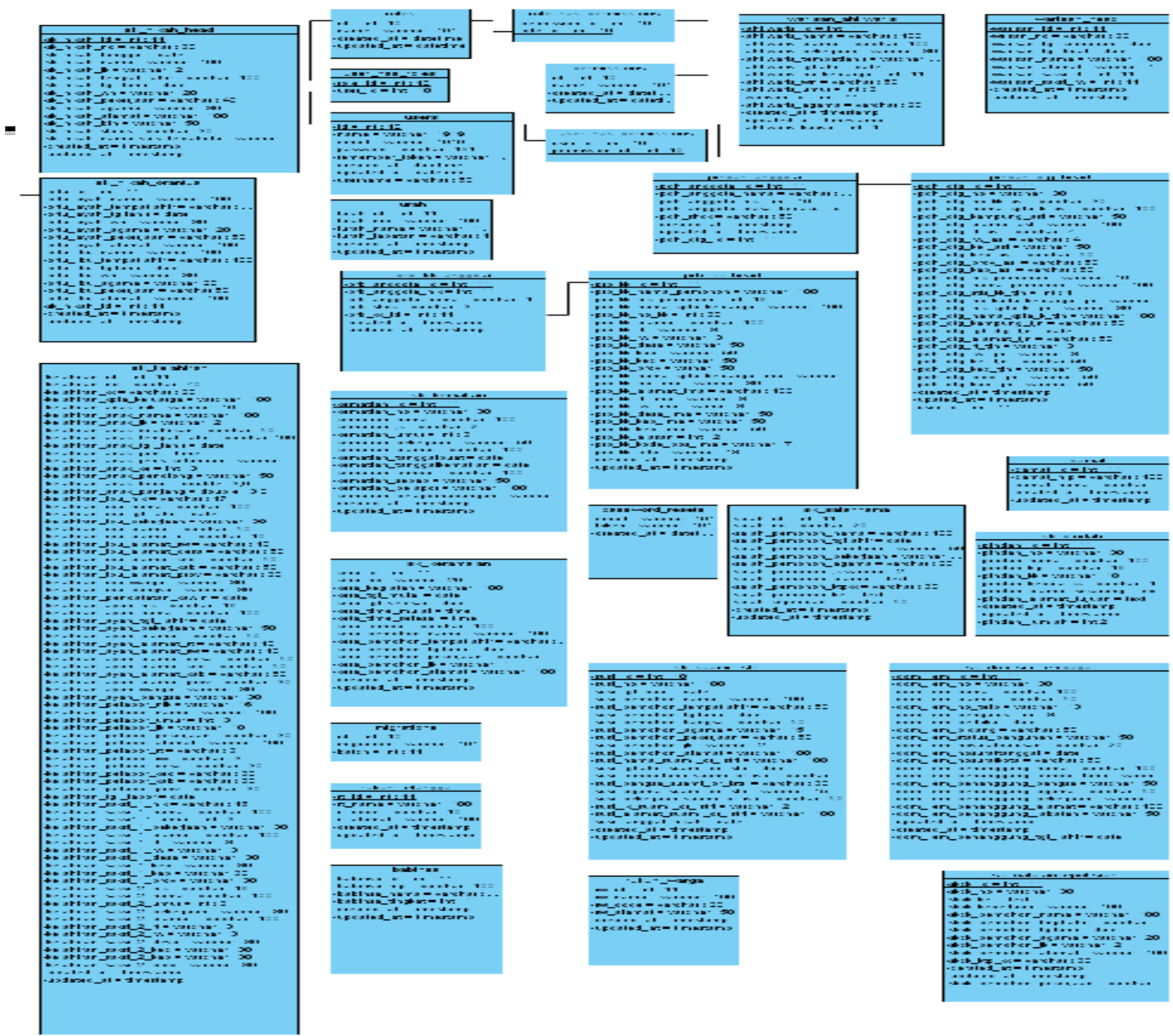

Gambar 3. Class Diagram rancangan Sistem Informasi Surat Pengantar

Class Diagram Rancangan Sistem Informasi Surat Pengantar yang menggambarkan rancangan basis data yang akan digunakan pada sistem.

\section{Perbedaan Prosedur Antara Sistem Berjalan dan Sistem Usulan}

Berikut ini adalah perbedaan prosedur antara sistem berjalan dengan sistem usulan yang ditunjukan pada tabel berikut :

\begin{tabular}{|c|c|}
\hline Sistem yang berjalan & Sistem yang diusulkan \\
\hline $\begin{array}{l}\text { 1. Dalampenginputan data form surat } \\
\text { masih menggunakan } \\
\text { Ms.Word/Ms.Excel, }\end{array}$ & $\begin{array}{l}\text { Dalam melakukan penginputan data form } \\
\text { surat hanya perlu membuka menu surat } \\
\text { baru pada sistem pengelolaan surat untuk } \\
\text { pembuatan surat. }\end{array}$ \\
\hline $\begin{array}{l}\text { 2. Dalam pencarian surat pengantar } \\
\text { dilakukan dengan mencari dalam } \\
\text { beberapa file folder yang tidak } \\
\text { tersimpan rapih sehingga memakan } \\
\text { waktu yang lama. }\end{array}$ & $\begin{array}{l}\text { Proses pencarian surat pengantar yang } \\
\text { dibutuhkan sangat cepat karena sudah } \\
\text { tersedia menu search dalam sistem } \\
\text { pengelolan surat. }\end{array}$ \\
\hline $\begin{array}{l}\text { 3. Dalam penyimpanan data belum } \\
\text { efektifkarena terdapat beberapa file } \\
\text { dan folder lain yang mengakibatkan } \\
\text { beresiko kehilangan file/folder surat. }\end{array}$ & $\begin{array}{l}\text { Penyimpanan data sistem menggunakan } \\
\text { database mysql sehingga dapat } \\
\text { menyimpan data dengan jumlah yang } \\
\text { sangat banyak. }\end{array}$ \\
\hline
\end{tabular}




\section{Tampilan Rancangan Sistem}

Dibawah ini adalah tampilan rancangan sistem surat pengantar :

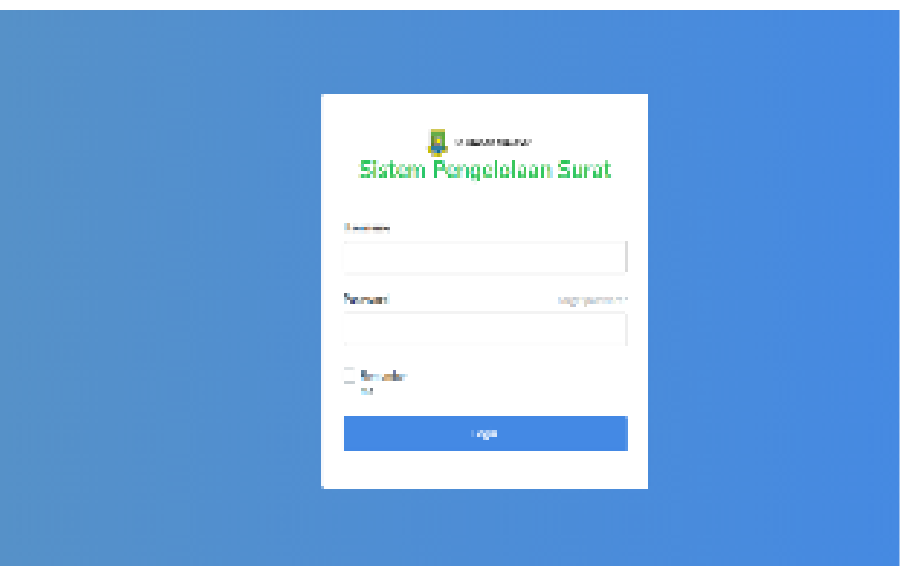

(1)
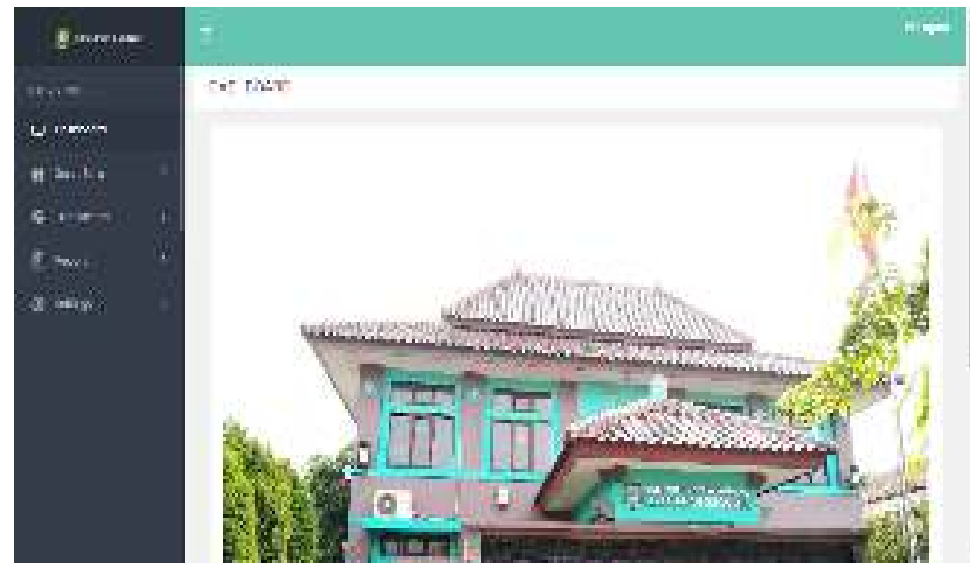

(2)

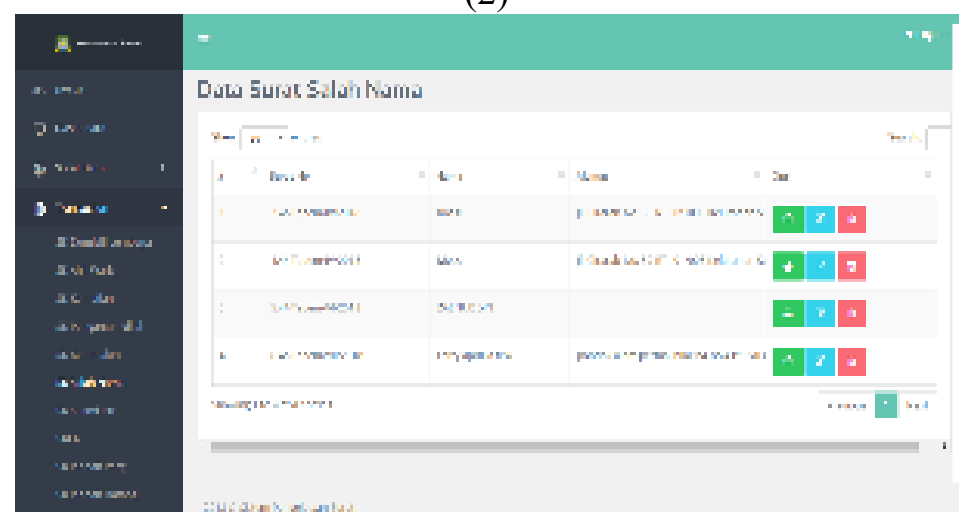

(3)
Untuk mengakses sistem ini sumua user akan menuju halaman login dan hanya yang memiliki akun username
Setelah berhasil melakukan login, maka user akan masuk ke halaman utama, Terdapat juga beberapa pilihan menu seperti SuArat Baru, Transaction, Report, dan Settings yang memudahkan user dalam memilih sesuai kebutuhan user. Berikut adalah tampilan home.

Pada tampilan ini dapat menampilkan data - data surat yang telah diinput dan dapat dilakukan print,edit,delete data surat. 


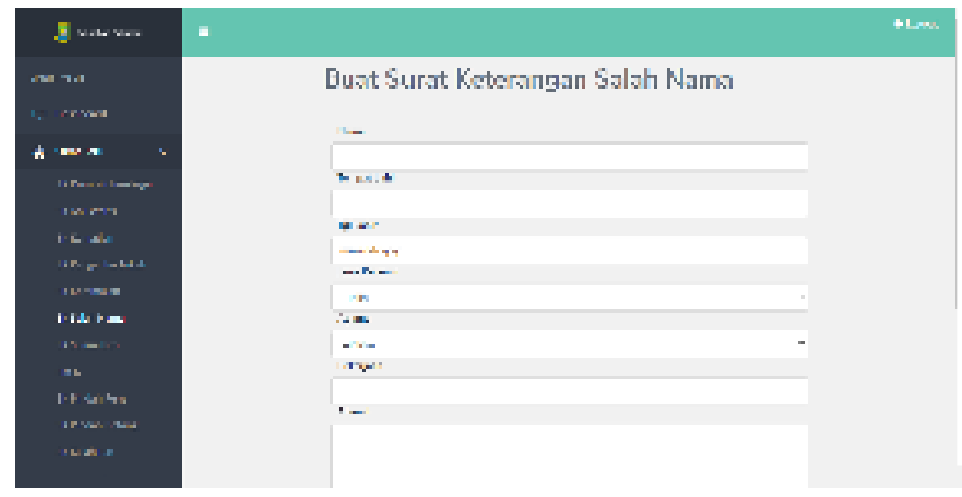

(4)

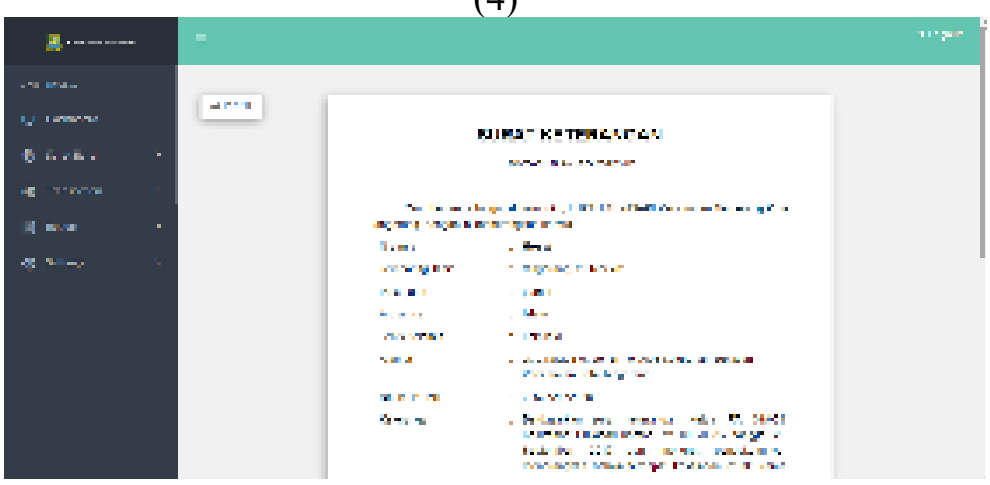

(5)
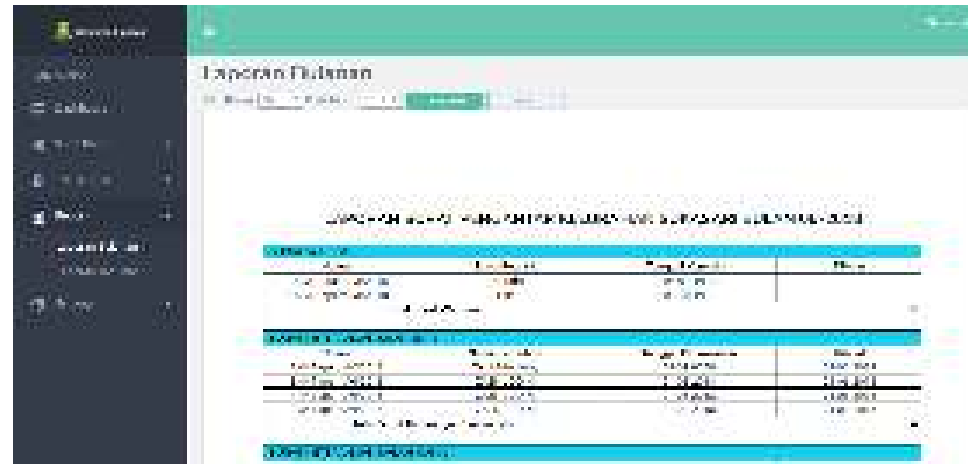

(6)
Tampilan ini adalah tampilan untuk user membuat surat yang dibutuhkan. Pada menu ini menampilkan pilihan menu beberapa surat yang akan dibuat sesuai permintaan masyarakat dan form- form surat yang akan diinput oleh user

Pada tampilan ini menampilkan surat yang sudah dibuat dan akan dilakukan print.
Pada tampilan ini user dapat melihat data laporan yang bisa dilihat berdasarkan bulan atau tahun dan dapat dilakukan print.

Gambar 3. (1) Tampilan Login. (2) Tampilan Home. (3) Tampilan Transaction. (4) Tampilan Surat Baru. (5) Tampilan Print Surat. (6) Tampilan Report

\section{KESIMPULAN}

Sistem informasi pembuatan surat pengantar pada kelurahan Sukasari Kota Tangerang memiliki manfaat untuk menunjang kinerja pelayanan yang lebih baik. Dengan sistem ini, pengolahan data surat pengantar lebih terintegrasi sehingga masyarakat yang ingin membuat surat pengantar dapat mengolah data secara cepat, tepat dan akurat. Pembuatan surat pengantar menjadi terdatabase sehingga mengurangi kesalahan atau human error. Tidak ada lagi penumpukan berkas-berkas yang dapat menimbulkan resiko kehilangan data. Sehingga proses pembuatan surat lebih tertata. Laporan yang di hasilkan menjadi lebih efektif. 


\section{SARAN}

Saran yang dapat disampaikan dalam penelitian ini adalah agar penelitian berikutnya dapat mengembangkan sistem ini menjadi lebih baik lagi. Maka, peneliti merekomendasikan sebagai bahan pertimbangan sebagai berikut:

1. Dalam penerapan sistem informasi surat sebaiknya didukung oleh perangkat yang memadai, baik dari segi peralatannya (software dan hardware) maupun sumber daya manusia agar sistem dapat berjalan secara maksimal.

2. Apabila sistem yang baru sudah berjalan maka perlu diperhatikan dan dilakukan evaluasi secara berkala terhadap sistem untuk selanjutnya diadakan perbaikan sesuai dengan perubahan dan perkembangan.

3. Melakukan pengembangan perancangan sistem informasi/aplikasi yang lain untuk menunjang kinerja pelayanan yang lebih baik.

\section{DAFTAR PUSTAKA}

[1] Hengki Tamando Sitohang. 2018. Sistem informasi pengagendaan surat berbasis web pada pengadilan negeri medan. Jurnal informatik pelita nusantara : Vol.3, No.1.

[2] Martono, Kartika, dan Putri Aullia. 2017. Aplikasi Jenjang Sosial Pendataan Kartu Keluarga Berbasis Web. Jurnal CCIT : Vol.10, No.2

[3] Sutopo, Priyo dan Arifin, Zainal dan Cahyadi, Dedi. 2016. "Sistem Informasi Eksekutif Sebaran Penjualan Kendaraan Bermotor Roda 2 Di Kalimantan Timur Berbasis Web". Kalimantan Timur: Universitas Mulawarman. Jurnal Informatika Mulawarman Vol. 11 No. 1 Februari 2016.

[4] Rosmila, Muh. Yamin, dan LM. Tajidun. 2016. Aplikasi Pembagian Harta Warisan Menurut Hukum Islam Dengan Menggunakan Metode Algoritma Genetika. Jurnal SemanTIK : Vol.2 No.2,

[5] Joko Agus Prawono, Anton Respati Pamungkas. 2015. Sistem Informasi Pengelolaan Surat Masuk Dan Surat Keluar Di Stmik Aub Surakarta

[6] Martono, Kartika, dan Putri Aullia. 2017. Aplikasi Jenjang Sosial Pendataan Kartu Keluarga Berbasis Web. Jurnal CCIT : Vol.10, No.2

[7] Kusumawati, Dewi dan Dwi Setiyani. 2017. Aplikasi Pembelajaran Iqro Berbasis Multimedia Pada Tk Islam Terpadu Al Mubarak Palu . jurnal JESIK (Jurnal Elektronik Sistem Informasi dan Komputer) : Vol.3, No.1 